\title{
Cost-Effective Design of Ringwall Storage Hybrid Power Plants: A Real Options Analysis
}

\author{
Sebastian Weibel ${ }^{\mathrm{a}}$, Reinhard Madlener ${ }^{\mathrm{b} *}$ \\ ${ }^{a}$ RWTH Aachen University, Templergraben 55, 52056 Aachen, Germany \\ ${ }^{b}$ Institute for Future Energy Consumer Needs and Behavior (FCN), School of Business and Economics / E.ON Energy Research \\ Center, RWTH Aachen University, Mathieustrasse 10, 52074 Aachen, Germany
}

\begin{abstract}
We study the economic viability and optimal sizing and siting of a hybrid plant that combines a ringwall hydro storage system with wind and solar power plants (ringwall storage hybrid power plant, RSHPP). A real options model is introduced to analyze the economics of an onshore RSHPP, an in particular of the varying storage volume in light of the stochastic character of wind and solar power, as well as the optimal investment timing under uncertainty. In fact, many uncertainties arise in such a project. Energy production is determined by the stochastic character of wind and solar power, and affects the optimal size of the storage device. Monte Carlo simulation is performed to analyze the following sources of uncertainty: (i) wind intensity and solar irradiation; (ii) future electricity price; and (iii) investment costs. The results yield the optimal size of the storage device; the energy market on which the operator should sell the electricity generated; numerical examples for two different RSHPP application scenarios; and a real options model for analyzing the opportunity to defer the project investment and thus to exploit the value of waiting.
\end{abstract}

(C) 2014 The Authors. Published by Elsevier Ltd. This is an open access article under the CC BY-NC-ND license (http://creativecommons.org/licenses/by-nc-nd/3.0/).

Peer-review under responsibility of the Organizing Committee of ICAE2014

Keywords: Pumped storage hydro power; Hybrid power plant; Real option; Irreversible investment; Risk and uncertainty;

\section{Introduction}

Due to the politically fostered, growing contribution of renewables, especially of wind and solar power, electricity supply fluctuations are increasing as well. To tackle this problem effectively, innovative energy storage concepts have been proposed. So-called 'ringwall storage' systems ([1]-[3]), which are based on the principle of pumped storage hydro power plants, are such a novel concept. A combination of this type of storage plant with wind turbines and photovoltaic (PV) systems is referred to as a ringwall storage hybrid power plant (RSHPP). This paper introduces a real options (RO) model [4]

* Corresponding author. Tel.: +49-241-80-49-820; fax: +49-241-80-49-829.

E-mail address: RMadlener@eonerc.rwth-aachen.de. 
aimed at analyzing the economic viability of, and the optimal investment time for, an RSHPP in dependence of its stochastic energy production and the future evolution of the electricity price.

Conventional pumped storage power plants (PSPP) can only be built in regions ensuring a certain height difference between the upper and lower basins. These regions are often far away from coastal areas, where most of the onshore and the offshore wind energy is to be generated. In Germany, as well as in Europe, there are only a few favorable sites left. Thus, the installed capacity has remained nearly constant in recent years. All of these facets show that new energy storage concepts will be essential for the future development of an energy supply system with a growing share of renewable energy. Artificially constructed PSPP, such as RSHPP, can help to balance load fluctuations of wind and solar power supply.

With such a large-scale project, a number of uncertainties arise that need to be taken into account. These include the investment costs, which are risky because of a lack of experience and the fact that an enormous amount of earth moving is necessary to construct the ringwall and the upper and lower basins.

In our analysis, an RSHPP combined with wind turbines and PV cells are examined, so the stochastic character of wind and solar power is an important determining factor for the energy production. It is also decisive for filling up the storage device, and influences the device's size. The required storage volume itself has a significant influence on the project's profitability, too. A further economic uncertainty is the future development of the electricity prices on the various energy markets. The operator of an RSHPP has to choose on which energy market to offer his generated power. He can offer it on the day-ahead or the intraday spot market, or, alternatively, he can enter into long-term contracts on the futures market. Still another possibility is that a large-scale RSHPP offers its capacity on the balancing energy market.

During the long period of planning and constructing, many issues can arise that may affect the project's economic viability. At several times, the investor has the opportunity to adapt his project to the changing conditions. If he expects improved economic conditions in the future, he could defer his investment to a later period, or cancel the project if the expected deficit exceeds the costs of abandonment.

Classical investment analysis using the net present value (NPV) approach does not adequately address uncertainty and ignores the various options that an investor can exercise, i.e. the value of management flexibility. Hence traditional analyses may underestimate a project's value [5] (p.63). The NPV rule implicitly assumes absence of flexibility in decision making, although the investment may be either (partly) reversible or a now or never decision. This inflexibility assumption violates fundamental characteristics of many real investment decisions [4] (p.6). Real options analysis (ROA) helps to more appropriately integrate uncertainties and the flexibility of exercising different kinds of options into the economic examination. This paper introduces an ROA model that allows an investigation of the economic viability of an RSHPP, regarding the stochastically varying electricity supply from wind and solar power. It also determines the optimal scale of the power plant and the storage volume, depending on the application, as well as the optimal timing of investment.

\section{The Ringwall Storage Hybrid Power Plant}

RSHPP concepts are based on the fundamental principle of pumped storage hydro power systems. But unlike PSPP, RSHPP are independent from many natural preconditions and can even be built on flat terrain or in shallow coastal waters. Today, a few proposals already exist for both onshore and offshore real world systems, and several companies and institutions have developed concepts for artificial power storage plants. The considerations in our study are primarily based on the (onshore) concept introduced by Popp ([1]-[3]), who also coined the term 'ringwall storage' plant.

The hybrid nature of the RSHPP investigated here results from the installation of wind turbines and PV systems. Wind turbines are set up on the wall and all around the lower basin. The PV modules can best be installed on the southern side of the ringwall; additional floating panels can be placed on the surface of 
the upper reservoir. The combined use of wind and solar power provides a great advantage: the daily and annual fluctuations of wind and solar power can be partially compensated. During the autumn and winter months the wind energy production is higher than in summer; vice versa, there is more PV energy in spring and summer than in winter. Iterative analysis revealed that for most European locations a ratio of $80 \%$ wind power and $20 \% \mathrm{PV}$ power will incur the least required storage capacity [1] (p.106f). In addition to power generation and storage, there are further possible usages of the large basins. The lakes and the surrounding areas could be used as a recreational resort or for other touristic purposes. Provided that the water quality is adequate, the basins could serve as a drinking water reservoir. Note that the circular shape of the ringwall plant is not a prerequisite; it could be adapted to the natural preconditions if needed (or desired). For simplicity, in our analysis we have assumed a circular construction of the RSHPP.

The required energy storage capacity is determined by the application of the plant. A commonly used measure is the day load, which represents the daily average amount of electricity provided [1]. Per megawatt of electricity generated, a storage capacity of $24 \mathrm{MWh}$ is required to provide one day of load. The water volume required depends on the potential energy stored in the water and can be determined by the average height difference between the upper and the lower reservoir. The area needed for an RSHPP depends on the fluctuation of the water level, which is related to the exchange volume between the two basins; the higher the fluctuations are, the lower the required space is. Currently, for instance, the largest German PSPP, Goldisthal, has a storage volume of about 12 million $\mathrm{m}^{3}$ of water, providing an energy storage capacity of about $8.5 \mathrm{GWh}$. Doubling the diameter results in a quadrupling of the surface, whereas doubling the height leads to an eightfold increase in the storage volume; taken together, this results in a 16-fold increase in storage capacity [1] (p.54). Consequently, huge RSHPPs are technically, energetically, and economically most beneficial, although it may be quite difficult to realize such projects.

In our analysis, we investigate two scenarios: (1) a balancing application, where the RSHPP is used for balancing off the volatility of wind and PV and delivers a predetermined, constant amount of power for one week; (2) a flexible application, where electricity is offered on the day-ahead spot market for profit maximization by exploiting the difference between the ELIX peak and the ELIX night price differences.

\section{Determining Factors of Cost-Effectiveness}

The economic viability of an RSHPP is essentially determined by two main factors: the amount of electricity generated, depending on wind velocity and solar irradiation, and the revenues from selling the electricity output, which depend on the expected electricity prices of the different energy markets. Several other aspects influence these key factors, including the investment costs of all systems, the cost of capital, the technical lifetimes of the devices involved, subsidies or other governmental support etc. The specific costs for the RSHPP result from the required energetic storage capacity and the correlation of diameter, average height difference, and level fluctuations of the upper and the lower basin. Generally, specific cost decline with increasing height difference, and growing level fluctuation. For simplicity, in our study the technical and economic lifetime of all components of the entire RSHPP is set at 30 years. This value corresponds to the lifetime of wind turbines and PV system. See [6] for further details.

\section{Main Results, Conclusion and Outlook}

The recent developments in the energy sector will also continue in the future. Especially with regard to the nuclear phase-out in some countries, including Germany, and the international targets for the reduction of the $\mathrm{CO}_{2}$ emissions, renewable energy is becoming more and more essential in energy systems. Since the energy production of wind turbines and PV systems cannot be predicted accurately and is also subject to large fluctuation, energy storage systems will be indispensable in the future. The RSHPP 
provides an innovative and useful concept for storing energy. However, an economic valuation, as was undertaken in our study, is difficult to assess. The two exemplified application scenarios depict only a small fraction of the possible application range of an RSHPP.

The balancing application scenario presented first represents a realistic utilization of the plant. Also, the described dimension seems to be conceivable for a real-life construction. Nevertheless, the economic analysis of this RSHPP does not yield a positive result. Due to the purpose of balancing the load fluctuations that arise from the varying wind and PV energy production, the operator cannot use the advantages of the energy market and sell the energy at peak-load prices, which is a major reason why the value of the PVCF of $€ 456.5$ million is relatively low. The highly negative base case NPV is the result of this low PVCF and of the enormous investments costs. Due to the high implementation costs and the relatively low present value of the cash flows, the real option value of $€ 382.4$ million is not high enough to compensate the negative value of the NPV. A realization of an RSHPP operating at this balancing scenario is almost inconceivable. This also becomes apparent when the results of the optimal investment timing problem are regarded. The optimal time to execute the RO is found to be 56 years in the future. Also, the profitability index indicates that the NPV turns positive in 40 years at the earliest. These results show that in the absence of governmental funding support an RSHPP is unlikely to be realized in the near future. Our analysis examines the economic viability of the certain project excluding any kind of subsidies, in order to depict the mere competitiveness of the project. In reality, such projects are likely subsidized, either with investment grants or with electricity price premiums, especially if it operates to provide balancing. Such subsidization could make the investment in this RSHPP profitable.

In contrast, an RSHPP operated in a flexible application scenario offers some advantages. The operator has the ability to sell the electricity generated at peak-load prices. In this scenario, the storage device is no longer used to balance the load fluctuations of wind and solar power. Rather, the RSHPP is used to raise revenues. Thus, this RSHPP does not help to mitigate the increasing problems of fluctuating energy supply (on the contrary, these problems may even be exacerbated). Nevertheless, the economic viability is analyzed to obtain a comparative value to the first scenario. The present value of the future cash flows is $€ 1,403.8$ million, and thus about three times higher than the one found for the balancing scenario. Although the base case NPV is negative, the high real option value of $€ 1,216.3$ million turns the negative value into a positive strategic NPV. The optimal executing time for the option is indeed beyond the maturity of the option, but the profitability index indicates a positive NPV after three years. Note that this analysis also ignores any kind of governmental grant. Applying real options theory, an investment in this RSHPP is found to be profitable, even without public funding.

Since novel energy storage facilities will be required in the near future, it is quite likely that a first demonstration RSHPP plant will be realized in the coming years. Based on such an experimental plant, it can then be investigated in further detail whether this technology is economically viable or not.

\section{References}

[1] Popp M. Speicherbedarf bei einer Stromversorgung mit erneuerbaren Energien. Heidelberg: Springer, 2010.

[2] Popp M. Berechnungstool zur Auslegung eines Ringwallkraftwerks, 2012. [Online] Available at: http:// www.ringwallspeicher.de/Ringwall-Berechnungstool.htm [retrieved April 20, 2013].

[3] Popp M. Regenerativstrom im Ringwall speichern. BWK - Das Energie-Fachmagazin 2010;12:53-8.

[4] Dixit AK, Pindyck RS. Investment under uncertainty. Princton: Princton University Press, 1994.

[5] Mun J. Real options analysis. 2 ed. Hoboken: Wiley \& Sons, 2006.

[6] Weibel S, Madlener R. Cost-Effective Design of Ringwall Storage Hybrid Power Plants: A Real Options Analysis, FCN Working Paper No.17/2013, Institute for Future Energy Consumer Needs and Behavior, RWTH Aachen University, December. 


\section{Biography}

Sebastian Weibel is a student of mechanical engineering economics (specialization: energy technology) at RWTH Aachen University, Germany. Dr Reinhard Madlener is full professor of energy economics and management at RWTH Aachen and codirector of the energy section of the Jülich Aachen Research Alliance (JARA Energy). He teaches energy economics, environmental economics, economics of technical change, and economics of technological diffusion. His main research interests lie in energy economics and policy as well as the adoption and diffusion of technological (energy) innovations under uncertainty. 